\title{
Reproductive characters of interspecific hybrids between Trifolium repens $L$. and T. nigrescens Viv.
}

\author{
A. H. MARSHALL*, T. P. T. MICHAELSON-YEATES, P. ALUKA \& M. MEREDITH \\ Institute of Grassland and Environmental Research, Plas Gogerddan, Aberystwyth, Dyfed, SY23 3EB, U.K.
}

\begin{abstract}
The amphidiploid Trifolium repens L. $(2 n=4 \mathrm{x}=32)$ is one of the most agronomically important of the 250-300 species in the genus Trifolium. Seed production is, however, variable and often poor, because of a number of interacting reproductive and climatic factors. Improvement to those characters influencing seed production may be achieved by interspecific hybridization using a closely related species within the genus. One species which has been demonstrated to have a close affinity with $T$. repens is the annual $T$. nigrescens $(2 n=2 \mathrm{x}=16)$, a prolific flower producer with a less intermittent pattern of flowering than $T$. repens. Specific cross-combinations of $T$. repens and $T$. nigrescens readily produced hybrids without the need of embryo culture. Some $F_{1}$ hybrids produced large numbers of seed when backcrossed to T. repens. Chromosome counts, isoenzymes and leaf markers confirmed that these were true hybrids. The $\mathrm{F}_{1} \mathrm{~s}$ and $\mathrm{BC}_{1} \mathrm{~s}$ were vigorous plants demonstrating intermediate reproductive characters inherited from the two parental species. This novel approach may be a means of extending the range of heritable variation useful in the breeding and selection of $T$. repens.
\end{abstract}

Keywords: interspecific hybrids, reproductive growth, Trifolium nigrescens, Trifolium repens.

\section{Introduction}

Trifolium repens $\mathrm{L}$. (white clover), a self-incompatible perennial species $(2 n=4 x=32)$, is the most important forage legume in temperate northern Europe. In a mixture with grasses it provides herbage of a high nutritive value and contributes a considerable quantity of nitrogen to the sward (Erith, 1924). The main objective of $T$. repens breeding programmes has been to improve important agronomic characteristics such as dry matter production and persistency. However, the commercial success of a variety also depends upon its ability to produce reasonable quantities of seed. Unfortunately, within the U.K. seed yields of $T$. repens are variable and often low (Marshall, 1994).

Several factors contribute to the low seed yields of $T$. repens. Climatic conditions, and in particular excessive rainfall during pollination and at harvest, have a major detrimental effect (Marshall, 1994). The growth of the plant during the reproductive phase is also important, as the indeterminate flowering and intermittent pattern of flowering along the stolon influence the number of ripe inflorescences at harvest and can cause variation in seed yield.

*Correspondence.
Inflorescences, the main seed yield component (Marshall, 1994), are produced from axillary buds in the axils of leaf primordia on stolons (Thomas, 1981). A stolon node may produce an inflorescence, may be vegetative and produce a secondary or tertiary stolon or remain dormant. Inflorescences may occur at one or two nodes along a stolon, with a gap of several nodes followed by more reproductive nodes (Thomas, 1981). Consequently, inflorescences are produced over a prolonged period and only a proportion of them will contain mature seed at any one time. These characteristics make it difficult for seed growers to optimize the harvest date, as only a proportion of the mature inflorescences is harvested (Marshall et al., 1989).

Improvements to the characters that influence seed production may be achieved by selecting genotypes with the desired floral characteristics from within $T$. repens (Hill et al., 1989). An alternative approach is to use interspecific hybridization. This is a means of increasing the genetic variability available for selection beyond the normal range of a single species and of combining useful traits from different species. Within the Trifolium genus, there are more than 250 species and a number of these, including $T$. occidentale, $T$. uniflorum and T. ambiguum, can produce occasional hybrids with $T$. repens (Gibson et al., 1971; Williams, 
1978). Trifolium nigrescens Viv. (Ball clover), a selfincompatible annual $(2 n=2 \mathrm{x}=16)$ which has a number of useful reproductive characters, has also been shown to be cross-compatible with $T$. repens (Trimble, 1951; Keim, 1953; Hovin, 1962). It is a prolific producer of inflorescences and appears to have a less intermittent pattern of flowering than $T$. repens. Observations suggest it may also be particularly attractive to insect pollinators.

The present paper describes the development of hybrids between $T$. repens and $T$. nigrescens and compares the reproductive characters of the two species and their related hybrids. Particular attention is given to flowering characteristics and the relative influence of the $T$. nigrescens and $T$. repens genomes on these and on other traits associated with seed production.

\section{Materials and methods}

\section{Production of hybrids}

In summer 1990, individuals from three populations of $T$. nigrescens were crossed to a large number of $T$. repens genotypes from widely differing populations. With $T$. nigrescens as the pollen parent, most crosses produced some seed. No seed was produced in any of the reciprocal crosses. Embryo rescue techniques were used for the first few crosses, but this proved unnecessary, as healthy seed developed in situ. There was considerable variation in cross-compatibility, but two interspecific combinations of accessions gave consistently high seed set, averaging 1.6 seeds per pod.

Material for further work was derived from one of these two relatively successful combinations. Five hand-crosses were produced between Ac3715, a prolific inflorescence producer and high seed yielding population of $T$. repens collected from Southern Ireland and Ah1524, a population of T. nigrescens from Portugal. Table 1 shows that the seed set in each of the crosses was similar to the normal seed set found in $T$. repens (Marshall, 1994). As T. repens is self-incompatible (Williams, 1925), all crosses were carried out without emasculation.

In April 1991, $80 \mathrm{~F}_{1}$ hybrid seeds from the above hand-crosses were sown into a John Innes No. 2 loambased compost in a glasshouse. The seed germinated readily, producing 50 healthy seedlings, and cytological examination confirmed that they were triploid $(3 x=24)$. When these hybrid plants began flowering they were placed outside the glasshouse and surrounded with a wide range of $T$. repens genotypes. Some of these white clover plants contained homozygous leaf markers (red leaf, red midrib and inverted V). Each of these distinctive leaf markers is controlled by a single dominant gene and was used as a genetic marker (Corkill, 1971). During the summer the plants were pollinated by bumble bees and honey bees. Ripe inflorescences were harvested from each of the 50 hybrid plants. Of these, 23 plants produced no seed, 12 plants produced $2-3$ seeds, nine plants produced 30-40 seeds and six plants produced $100-200$ seeds. Chromosome counts, isoenzyme analysis and leaf marker genes (see later) indicated that seed was produced as a result of backcrossing between the $F_{1}$ hybrids and $T$. repens rather than intercrossing among the $F_{1}$ s. Backcross seed $\left(B C_{1}\right)$ from individual $F_{1}$ plants was bulked.

\section{Isoenzyme analysis}

Thirty seeds of each parent species and derived $F_{1}$ and $\mathrm{BC}_{1}$ hybrids were scarified and sown in shallow boxes $(51 \times 38 \times 8 \mathrm{~cm})$ containing John Innes loam-based compost in a glasshouse at $15^{\circ} \mathrm{C}$. After 10 weeks, a young leaf was collected from 20 plants within each of the four groups. Each leaf was crushed in a buffer consisting of two drops of $0.05 \mathrm{~m}$ tris/mercaptoethanol at $\mathrm{pH}$ 7.2. The crude extract from each sample was then absorbed onto $9 \times 2 \mathrm{~mm}$ paper wicks. Starch gel electrophoresis was used to separate the isoenzymes as described by Michaelson-Yeates (1986).

Table 1 Mean number of seeds/floret from hand-crosses between Trifolium repens and T. nigrescens

\begin{tabular}{|c|c|c|c|c|c|}
\hline \multirow[b]{2}{*}{ Genotype cross } & \multicolumn{2}{|c|}{ Inflorescence 1} & \multicolumn{2}{|c|}{ Inflorescence 2} & \multirow[b]{2}{*}{ Mean seeds/floret } \\
\hline & Florets & Seed & Florets & Seed & \\
\hline Ac3715 (2) $\times$ Ah1 $524(1)$ & 38 & 55 & 54 & 99 & 1.67 \\
\hline $\operatorname{Ac} 3715(4) \times \operatorname{Ah} 1524(2)$ & 29 & 66 & 25 & 31 & 1.80 \\
\hline Ac3715 (6) $\times$ Ah $1524(5)$ & 46 & 74 & 30 & 17 & 1.20 \\
\hline Ac3715(9) $\times$ Ah1524(7) & 36 & 89 & 40 & 76 & 2.17 \\
\hline $\operatorname{Ac} 3715(10) \times \operatorname{Ah} 1524(8)$ & 40 & 21 & 43 & 78 & 1.19 \\
\hline
\end{tabular}


The three isoenzymes investigated were phosphoglucoisomerase (PGI) which catalyses the reversible isomerization of glucose 6-phosphate and fructose 6-phosphate, leucine aminopeptidase (LAP) which is an exopeptidase that hydrolyses the n-terminal residues of peptides, and amylase, an enzyme that hydrolyses starch. These were assayed in the dark at room temperature. After an hour, zones of enzyme activity (PGI and LAP) appeared on the gels as blue and red bands respectively. For the amylase enzyme the gel was left in ethanol overnight, and banding patterns due to the hydrolysis of the starch were visible after $12 \mathrm{~h}$.

\section{Experimental plant material}

On the 6th January 1992, 50 seeds of each of $T$. repens, $T$. nigrescens, $\mathrm{F}_{1}$ and $\mathrm{BC}_{1}$ hybrids were spread on wet germination pads and placed in a germination tank maintained at a temperature of $20^{\circ} \mathrm{C}$. Most seeds had germinated after three days, when they were transplanted into Jiffy pot trays containing a John Innes loam-based compost. The trays were kept in a glasshouse maintained at a day/night temperature of $15 /$ $5^{\circ} \mathrm{C}$. On the 9 th March, they were repotted, singly, into $9 \mathrm{~cm}$ diameter pots. Chromosome counts were made on the $F_{1}$ and $\mathrm{BC}_{1}$ hybrids by pretreating root tips for 5 $h$ in $\mathrm{H}_{2} \mathrm{O}$ at $0-2^{\circ} \mathrm{C}$, fixing in acetic acid:ethanol $(1: 3)$ and then staining in Feulgen (Meredith, pers. comm.). All $F_{1}$ plants that were used in the following experiments were triploid $(3 \mathrm{x}=24)$. Chromosome counts in the $\mathrm{BC}_{1}$ plants showed numbers between 28 and 30 , and 15 per cent of them contained one of the distinguishing leaf markers from the pollen parent, $T$. repens. Plants of the parental species and derived $F_{1}$ and $\mathrm{BC}_{1}$ hybrids are shown in Fig. 1.

\section{Experiment 1}

On the 23rd April, eight plants of each of the two species and the $\mathrm{F}_{1}$ and $\mathrm{BC}_{1}$ hybrids were repotted into $12.5 \mathrm{~cm}$ diameter pots. The pots were placed in a controlled environment in which the day/night temperatures were maintained at $20 / 15^{\circ} \mathrm{C}$. The pots were placed on saucers for watering and arranged in a fully randomized design. The light regime of $16 \mathrm{~h}$ was provided by an irradiance of $530 \mu \mathrm{mol} \mathrm{m} \mathrm{m}^{-2} \mathrm{~s}^{-1}$ supplied by a bank of warm white fluorescent tubes. A vapour pressure deficit of $6 \times 10^{-4} \mathrm{MPa}$ was maintained.

\section{Growth and development}

Though the lateral stems of $T$. nigrescens are not true stolons, 'stolon' has been used to describe their lateral stems and the similar structures of the hybrids.
On each pot, two primary stolons were marked with a ring of coloured wire behind the first trifoliate leaf. At weekly intervals throughout the experiment (13 weeks) the following parameters were recorded on each labelled stolon: (i) stolon length from the ring of coloured wire to the apical growing point; (ii) the total number of nodes; (iii) the number and position of secondary stolons arising from the labelled primary stolon; (iv) the total number and position of inflorescences on each stolon (node 1 being the first node after the ring and therefore the oldest). The number of inflorescences on each secondary stolon was also counted.

During the experiment, a total of four inflorescences in full bloom (inflorescences with all florets open) on unlabelled primary stolons were collected from each pot. All inflorescences were removed $2 \mathrm{~h}$ after the beginning of the light period. The florets were carefully removed and counted. One floret from the top, middle and bottom of each of two inflorescences was dissected and the length and width of each ovary was measured under the light microscope. Nectar volume and sugar concentration were measured on a subsample of 10 florets, by inserting a $10 \mu \mathrm{L}$ capillary tube into the lip of the floret. One tube was used to draw off the nectar from all ten florets, the length of the column of nectar was then measured and the per cent sugar content determined with a refractometer.

\section{Harvest measurements}

After 13 weeks, the labelled stolons were removed and the total length of the primary stolon and number of nodes, secondary stolons and inflorescences on the primary and secondary stolons recorded. The position of the reproductive nodes on each primary stolon was noted using the system described by Thomas (1981). The first node after the coloured wire was called node 1 and nodes distal to this 2, 3, 4 and so on. The number of nodes that bore an inflorescence at each position was then expressed as a proportion of the total nodes. On the rest of the plant, the numbers of inflorescences, primary stolons and the numbers of reproductive (those bearing inflorescences) and nonreproductive (not bearing inflorescences) stolons were recorded.

\section{Experiment 2}

On the 24th May 1992, eight plants of each of the two species and the $\mathrm{F}_{1}$ and $\mathrm{BC}_{1}$ hybrids were repotted into deep boxes $(51 \times 38 \times 15 \mathrm{~cm})$ containing the soil mix described in experiment 1 and transferred to an unheated glasshouse. On each plant two stolons were marked as in experiment 1 . At weekly intervals on each 
marked stolon, stolon length and the number of open inflorescences were recorded as well as the number of inflorescences on the whole plant. After eight weeks of measurement, all above ground material of each plant was harvested. The plants were separated into inflorescences and vegetative material (stolons and leaves). The numbers of fully opened and unopened inflorescences were counted, and inflorescences and vegetative material dried in an oven at $80^{\circ} \mathrm{C}$ for $12 \mathrm{~h}$ and weighed.

\section{Results}

\section{Isoenzyme analysis}

A previous extensive survey at the $P G I / 2$ locus of $T$. repens (Michaelson-Yeates, 1986) identified five alleles $(a, b, c, d, f)$ controlled by a single codominant gene that behaved in a normal Mendelian manner. These alleles gave rise to ten different banding patterns and because of gene dosage, genotypes containing different proportions of the same allele could be distinguished. The survey also revealed that out of the five alleles, only $c$ was homozygous. In this study (Fig. 2), the 20 T. repens plants produced four different isoenzyme banding patterns expressed by three alleles $(b, c, d)$. $T$. nigrescens was more uniform as only two different types of single band were observed, one of which corresponded to the position of the $c$ allele in $T$. repens. The same single band was the only one observed among the $20 \mathrm{~F}_{1}$ hybrids while the $\mathrm{BC}_{1}$ isoenzymes consisted of five different banding patterns. These were controlled by four alleles which were common to those that exist in $T$. repens.

The genetic control of LAP and amylase in $T$. repens is unknown. LAP isoenzyme banding patterns for both species and their hybrids are shown in Fig. 3, each

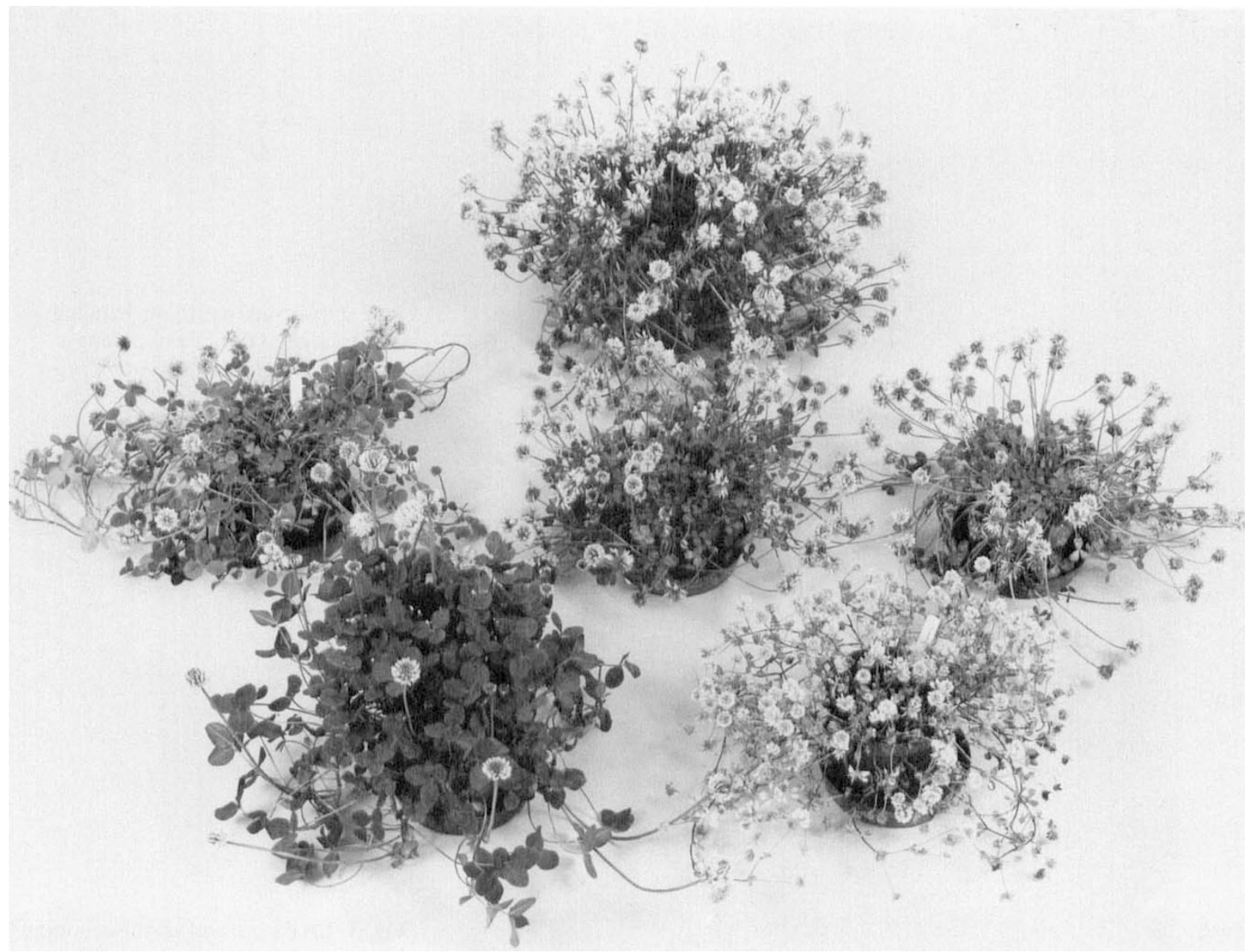

Fig. 1 Plants of Trifolium repens (bottom left), T. nigrescens (bottom right), $\mathrm{F}_{1}$ (three plants, middle row) and $\mathrm{BC}_{1}$ (top) hybrids at the onset of flowering. 
group being represented by three genotypes. The LAP survey showed clear differences in banding positions between $T$. repens and $T$. nigrescens. A distinct lower band was observed in all of the T. nigrescens plants but was absent from $T$. repens. The $\mathrm{F}_{1} \mathrm{~s}$ and $\mathrm{BC}_{1} \mathrm{~s}$ showed hybrid bands between the two parental species, alth', ugh the $\mathrm{BC}_{1} \mathrm{~s}$ often had a banding pattern similar to $C$. repens. A less concentrated lower band similar to $T$. nigrescens appeared in all the $F_{1}$ hybrids but was present in only 25 per cent of the $\mathrm{BC}_{1}$ plants.

Amylase banding among the species and their hybrids is shown at the bottom of Fig. 3. A single band showing variation was observed in all the $T$. repens material, but this was only faintly expressed among 15 per cent of the $T$. nigrescens plants. The amylase banding was very apparent in the $\mathrm{F}_{1}$ and $\mathrm{BC}_{1}$ plants.

\section{Experiment 1}

The general pattern of node production on the primary stolon was similar for all species and hybrids although stolons of $T$. repens had more nodes than those of $T$. nigrescens and all hybrids were intermediate (Fig. 4a). There were, however, some differences at the beginning of stolon growth as stolon nodes were visible in week one for both parent species and the $\mathrm{BC}_{1}$ but not until week two for the $F_{1}$.

There were few differences in the numbers of axillary buds/primary stolons until week four when numbers on $T$. nigrescens reached a peak and remained constant to the end of the experiment whilst those on $T$. repens and the hybrids continued to increase (Fig. 4b). From six weeks until the end of the experiment, the $F_{1} s$
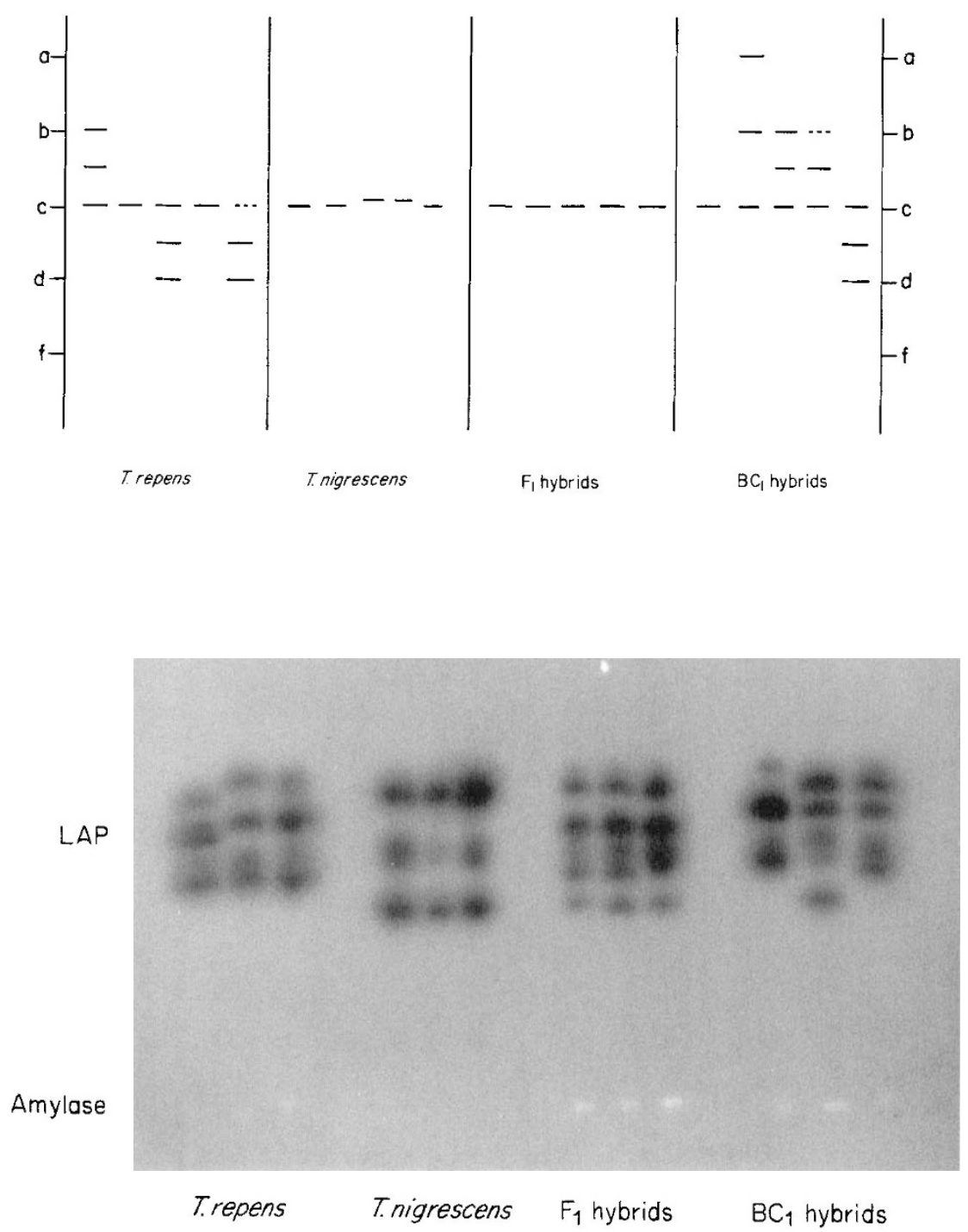

Fig. 2 Observed isoenzyme banding patterns at the $P G I / 2$ locus among a sample of five plants from each Trifolium species and associated hybrids.
Fig. 3 LAP (top) and amylase (bottom) isoenzyme banding patterns of, from left to right, Trifolium repens, $T$. nigrescens, $\mathrm{F}_{1}$ and $\mathrm{BC}_{1}$ hybrids. 
had more axillary buds than $T$. repens and the $\mathrm{BC}_{1}$ 's while $T$. nigrescens had fewer axillary buds.

Inflorescences were first visible in week three and from then $T$. nigrescens produced more inflorescences per primary stolon than $T$. repens and all hybrids (Fig. 4c). T. repens produced inflorescences later and also produced fewer inflorescences than the hybrids, which were intermediate between the parent species. $T$. nigrescens produced more inflorescences on secondary stolons than $T$. repens with the hybrids being intermediate (Fig. 4d). There were also differences in the date of appearance of inflorescences. Inflorescences were visible in week four for $T$. nigrescens, in week five for the hybrids but not until week seven for T. repens. The $\mathrm{F}_{1} \mathrm{~s}$ produced more inflorescences than $T$. repens and although the $\mathrm{BC}_{1} \mathrm{~s}$ also produced more inflorescences than $T$. repens these differences were not always significant.

At harvest, $T$. repens had more primary stolons/ plant than $T$. nigrescens and both hybrids, and $T$. nigrescens had fewer than all plants except the $F_{1} s$ (Table 2). T. repens also had more vegetative stolons and a higher proportion of vegetative stolons than $T$. nigrescens and the $F_{1}$ hybrids; the difference between $T$. nigrescens and the $\mathrm{F}_{1}$, however, was not significant. $T$. nigrescens had fewest reproductive stolons but the highest per cent reproductive stolons whilst $T$. repens had a lower proportion of reproductive stolons than $T$. nigrescens and all hybrids. Overall, $T$. nigrescens produced more inflorescences per plant than the hybrids, which were found to be similar, while $T$. repens produced fewest.

The pattern of flowering on the primary stolons is shown in Fig. 5. T. repens did not produce inflorescences until node nine and thereafter no more than 31 per cent of nodes at any position produced a reproductive bud. Few reproductive buds were observed beyond node 19. $T$. nigrescens, however, produced an inflorescence at node six and all nodes from eight to 12 were reproductive, after which there was then a gradual decline in the percentage of nodes forming reproductive buds until node 19. Generally, all the hybrids were intermediate between $T$. nigrescens and $T$. repens, having more inflorescences than $T$. repens but not as
Fig. 4 The number of (a) nodes/ primary stolon, (b) axillary buds/ primary stolon, (c) inflorescences/ primary and (d) inflorescences secondary stolon of Trifolium repens $(-\square-)$, T. nigrescens $(-\mathrm{O}-)$ and the $\mathrm{F}_{1}(-\triangle-)$ and $\mathrm{BC}_{1}\left(-\mathrm{O}_{--}\right)$hybrids. Vertical bars represent L.S.D. at $P=0.05$.
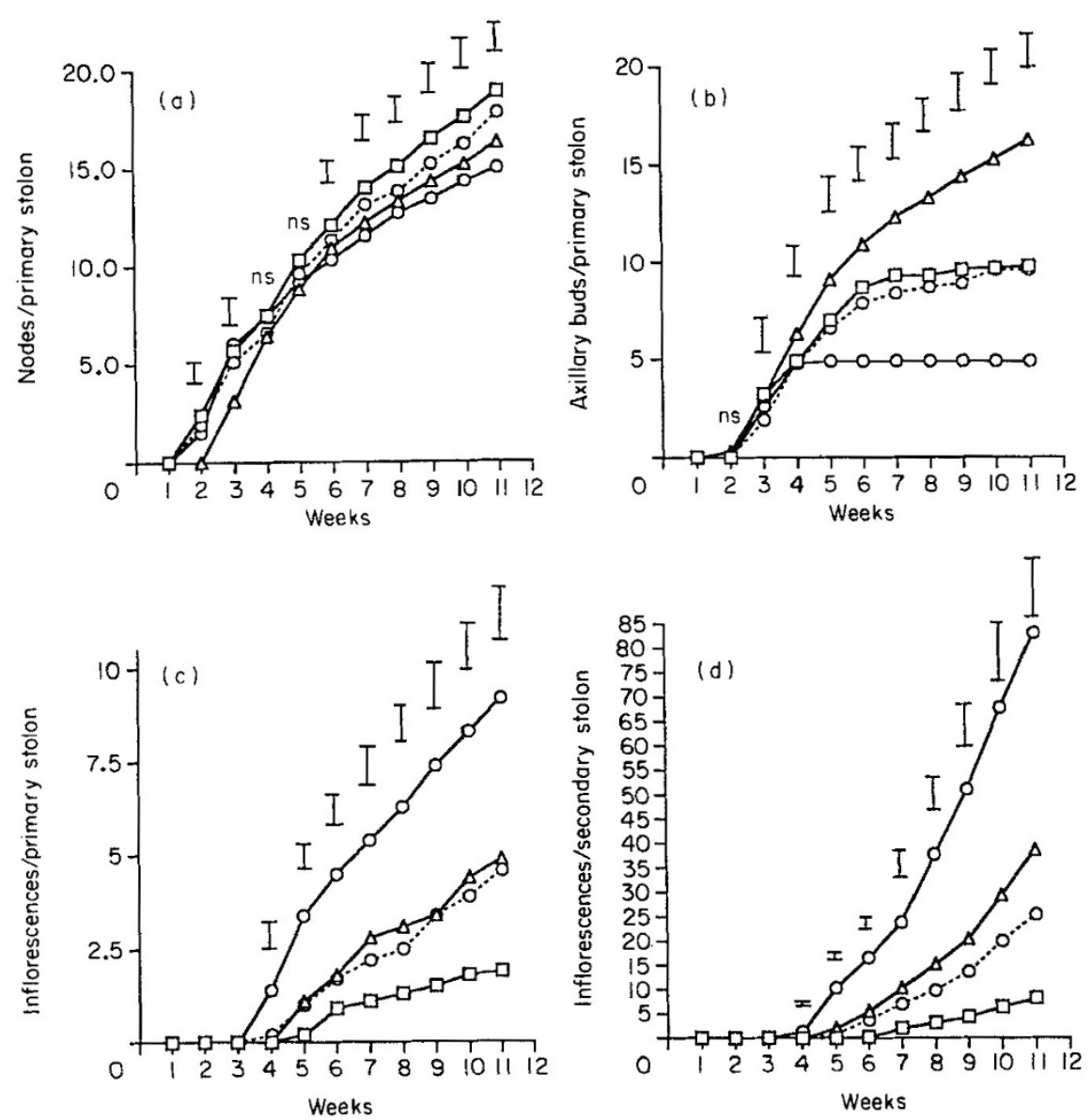
many as $T$. nigrescens. The $\mathrm{F}_{1} \mathrm{~s}$ produced a reproductive bud at node seven, reaching a maximum of 75 per cent at node 12 before declining until node 24 . The $\mathrm{BC}_{1} \mathrm{~s}$, however, produced the first reproductive bud at node five, reached a maximum of 50 per cent at nodes 13 and 14 before gradually declining until there were no reproductive nodes at node 23 . The number of florets per inflorescence was highest in $T$. repens and lowest in $T$. nigrescens with the hybrids intermediate (Table 3). Ovary length but not width (data not shown) also differed as $T$. repens had longer ovaries than $T$. nigrescens but not longer than the hybrids which were not significantly different from each other. $T$. repens also had more ovules/ovary than the $F_{1} s$ and both had more than the $\mathrm{BC}_{1} \mathrm{~s}$ and $T$. nigrescens, which were not significantly different from each other. Nectar production also differed as florets of $T$. repens and all hybrids produced more nectar than $T$. nigrescens, which had a significantly higher nectar sugar concentration than $T$. repens and the $\mathrm{BC}_{1}$ s but not the $F_{1}$ s.

\section{Experiment 2}

The numbers of harvested inflorescences of $T$. repens, $T$. nigrescens and the hybrids are shown in Table 4.T. nigrescens had many more inflorescences than $T$. repens and both hybrids, whilst $T$. repens had fewest inflorescences but only significantly fewer than the $F_{1} s$. There was no significant difference between the hybrids. This was reflected in the dry weight of the reproductive and vegetative components. The vegetative dry weight of $T$. repens was higher than $T$. nigrescens and all hybrids, whilst $T$. nigrescens was lower than the $\mathrm{BC}_{1} \mathrm{~s}$ but not the $\mathrm{F}_{1} \mathrm{~s}$. The per cent vegetative growth was lower in $T$. nigrescens than $T$. repens and all hybrids. $T$. nigrescens and the $\mathrm{BC}_{1} \mathrm{~s}$ had a higher inflorescence dry weight than $T$. repens but not the $F_{1} s$ and there was no difference between $T$. repens and the $F_{1} s$. T. nigrescens had the highest per cent inflorescence dry weight and $T$. repens the lowest, with both hybrids intermediate.

\section{Discussion}

Species hybridization is a means of extending the range of heritable variation, which can be exploited by the plant breeder. Brewbaker \& Keim (1953) were among the first to suggest interspecific hybridization of Trifolium spp. as a means of improving $T$. repens. They identified potential benefits in disease and pest resistance, persistency, root development and cold and drought tolerance The objective of the present study was to determine the potential for transferring reproductive characters from $T$. nigrescens to $T$. repens by interspecific hybridization.

Data presented in Table 1 confirmed results from other studies (Hovin, 1962), which demonstrated that by using $T$. repens as the female parent, specific genotype cross-combinations with $T$. nigrescens can produce large numbers of hybrids. In this paper we also describe the characteristics of a backcross generation to $T$. repens. Although the majority of $\mathrm{BC}_{1}$ plants were expected to be true backcrosses, it is possible that some intercrossing did occur among the $\mathrm{F}_{1} \mathrm{~s}$. Chromosome counts, isoenzyme analysis and leaf markers confirmed, however, the true origin of the $\mathrm{F}_{1} \mathrm{~s}$ and $\mathrm{BC}_{1} \mathrm{~s}$ used in this study. Among the $F_{1}$ hybrids, six plants produced as many as 200 seeds each, which is considerably more than the only other backcross hybrids thus far reported (Hovin, 1962). This is the first time that large numbers of hybrids have been produced by interspecific hybridization between these species and this enables an investigation of the morphological characteristics of the $\mathrm{F}_{1} \mathrm{~s}$ and the $\mathrm{BC}_{1} \mathrm{~s}$.

In perennial forage species such as $T$. repens, the correct balance between vegetative and reproductive

Table 2 Vegetative and reproductive stolons and inflorescences per plant of Trifolium species and hybrids

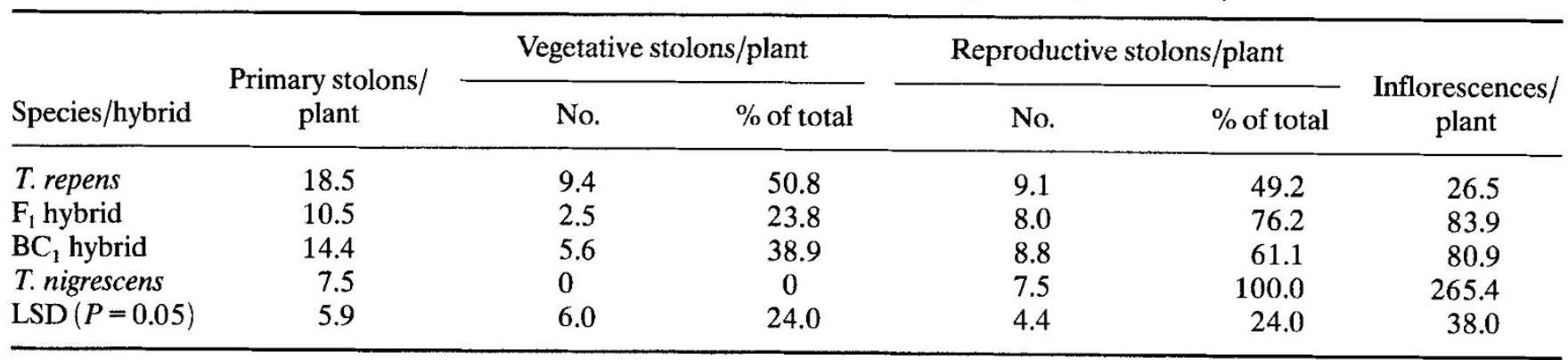



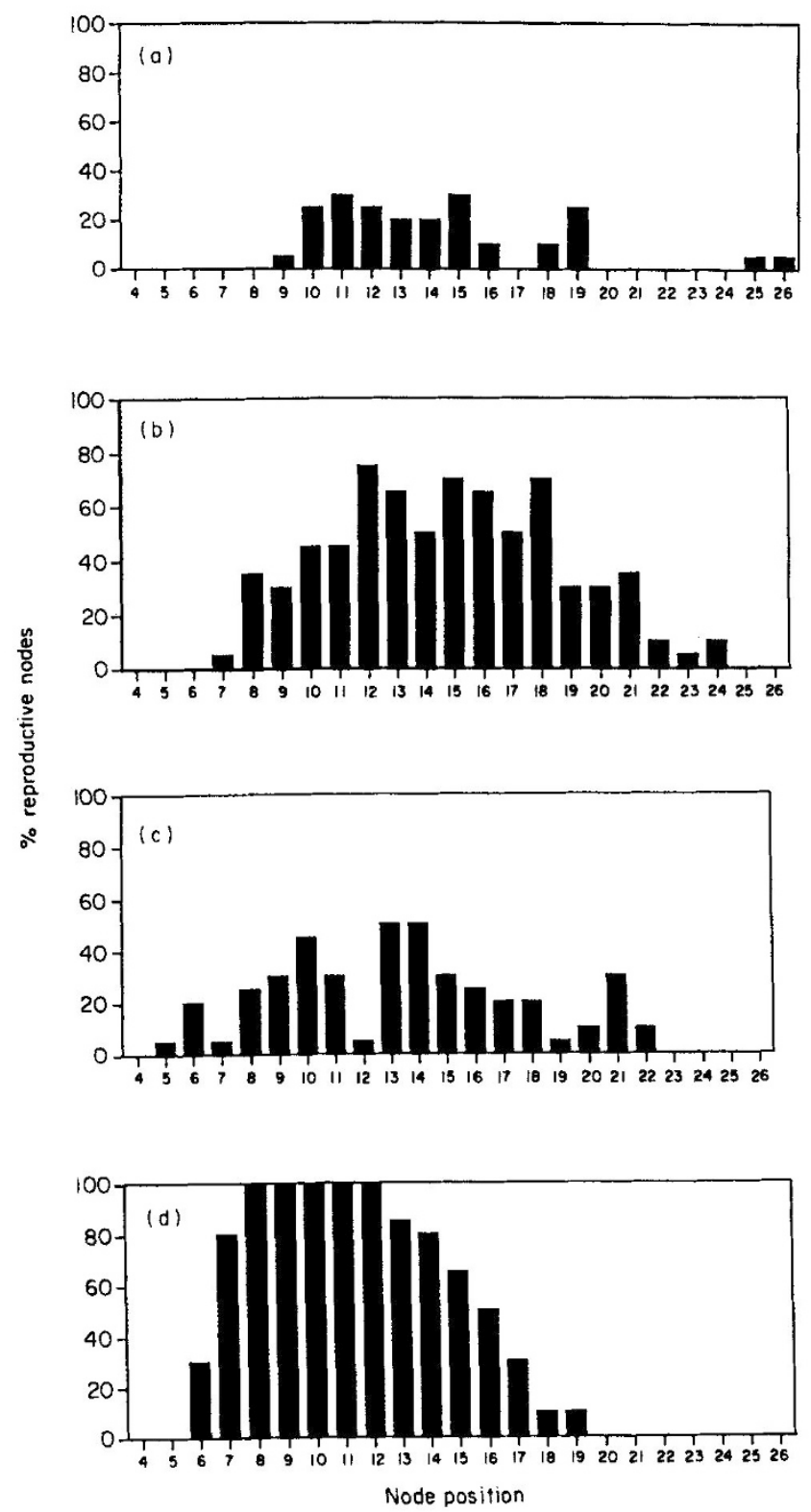

Fig. 5 The percentage of nodes producing a reproductive bud on the labelled primary stolon (node $1=1$ st node produced after the label and therefore the oldest) of (a) Trifolium repens, (b) $\mathrm{F}_{1}$ hybrid, (c) $\mathrm{BC}_{1}$ hybrid and (d) T. nigrescens. growth is important to ensure good forage production and the production of acceptable quantities of seed. In $T$. repens the number of reproductive nodes per stolon and their pattern along the stolon determine the number of ripe inflorescences at harvest, the main seed yield component (Hollington et al., 1989). To combine high seed yields, and good forage production and persistency, $T$. repens would ideally have stolons which change from vegetative to reproductive, producing a series of reproductive nodes, then revert to being vegetative. These vegetative nodes are important to ensure perenniality and persistency in the sward from one season to the next.

In both controlled environment and glasshouse experiments $T$. nigrescens produced an inflorescence at almost every node and, once flowering began, no secondary stolons were produced. In contrast, $T$. repens produced fewer inflorescences and the pattern of flowering on the primary stolon was intermittent. The hybrids had reproductive characters inherited from both parental species. Their pattern of flowering was intermediate between the parental species, though the $\mathrm{BC}_{1} \mathrm{~s}$ had a pattern more like that of $T$. repens. $T$. nigrescens had a more concentrated flowering pattern and therefore is likely to produce more ripe inflorescences at harvest. The $F_{1}$ hybrids were intermediate between the two species, and even the $\mathrm{BC}_{1} \mathrm{~s}$ had more inflorescences per plant and per stolon than $T$. repens. In practice, seed yield is the product of several yield components (Marshall, 1994), of which inflorescence number is the most important. The $\mathrm{F}_{1} \mathrm{~s}$ and $\mathrm{BC}_{1} \mathrm{~s}$ had smaller inflorescences with fewer florets and fewer ovules per floret than $T$. repens; however, their reproductive potential, as a product of the individual components, was considerably higher than that of $T$. repens. The reproductive characters of the $F_{1}$ hybrids lie close to the mid-parent indicating little overall dominance, but as expected, the expression of characters in the $\mathrm{BC}_{1} \mathrm{~s}$ was, in general, shifted towards $T$. repens.

It is important, however, to combine the desired reproductive characters with those vegetative characters that already exist in $T$. repens. The number

Table 3 Reproductive characters of Trifolium species and hybrids

\begin{tabular}{lcccc}
\hline Species/hybrid & $\begin{array}{c}\text { Florets/ } \\
\text { inflorescence }\end{array}$ & $\begin{array}{c}\text { Ovules/ } \\
\text { ovary }\end{array}$ & $\begin{array}{c}\text { Nectar volume/ } \\
\text { 10 florets (nL) }\end{array}$ & $\begin{array}{c}\text { Nectar sugar } \\
\text { concentration(\%) }\end{array}$ \\
\hline T. repens & 63.8 & 5.7 & 1.5 & 42.7 \\
F $_{1}$ hybrid & 44.6 & 4.8 & 1.4 & 52.3 \\
BC $_{1}$ hybrid & 41.2 & 4.2 & 1.5 & 50.6 \\
$T$. nigrescens & 28.6 & 4.0 & 0.6 & 56.4 \\
LSD $(P=0.05)$ & 4.8 & 0.6 & 0.5 & 4.6 \\
\hline
\end{tabular}


Table 4 Inflorescence production and vegetative and reproductive dry weight for Trifolium species and hybrids (g)

\begin{tabular}{|c|c|c|c|c|c|}
\hline \multirow[b]{2}{*}{ Species/hybrid } & \multirow[b]{2}{*}{ Inflorescences/plant } & \multicolumn{2}{|c|}{ Vegetative } & \multicolumn{2}{|c|}{ Inflorescence } \\
\hline & & Dry weight $(\mathrm{g})$ & $\%$ of total & Dry weight $(\mathrm{g})$ & $\%$ of total \\
\hline T. repens & 67.0 & 385.0 & 98.3 & 6.6 & 1.7 \\
\hline$F_{1}$ hybrid & 460.0 & 123.0 & 86.0 & 20.0 & 14.0 \\
\hline $\mathrm{BC}_{1}$ hybrid & 283.0 & 205.0 & 89.0 & 25.3 & 11.0 \\
\hline T. nigrescens & 868.0 & 30.0 & 59.1 & 20.8 & 40.9 \\
\hline $\operatorname{LSD}(P=0.05)$ & 240.2 & 104.2 & 9.8 & NS & 9.8 \\
\hline
\end{tabular}

of nonreproductive nodes, vegetative stolons and nodal roots are all essential to ensure perenniality and persistency in the sward from one season to the next. Being an annual species, $T$. nigrescens does not require this characteristic and it is not surprising that no vegetative stolons and nodal roots were observed. The $\mathrm{F}_{1} \mathrm{~s}$ had more vegetative stolons than $T$. nigrescens, but no nodal roots. However, the $\mathrm{BC}_{1} \mathrm{~s}$ had more vegetative stolons than the $F_{1} s$ whilst retaining the same number of reproductive stolons as $T$. nigrescens. Although the $\mathrm{BC}_{1} \mathrm{~s}$ had fewer vegetative stolons than $T$. repens, it should be possible to combine characteristics which will ensure persistency similar to $T$. repens whilst increasing reproductive growth. Though there were no nodal roots in the $F_{1} s$, they were apparent in some of the $\mathrm{BC}_{1} \mathrm{~s}$, suggesting that the production of nodal roots may be controlled by recessive genes. It is clear that those characteristics which are associated with the annual species $T$. nigrescens (profuse flowering, absence of nodal roots) are dominant over the same characters found in T. repens. Further breeding work is necessary to determine the extent to which good vegetative characters may be maintained whilst seeking to improve reproductive growth. This will also necessitate an examination of hybrid-derived material under field conditions.

The characteristics which determine the attractiveness of an inflorescence to insect pollinators are largely unknown, but floral scent and nectar production are likely to be important. Previous observations suggest that $T$, nigrescens and the hybrids are particularly attractive to pollinators (Michaelson-Yeates, unpublished). In the present experiments, $T$. nigrescens produced relatively small amounts of nectar but of a higher sugar concentration than $T$. repens. There was no difference between the $\mathrm{F}_{1} \mathrm{~s}$ and the $\mathrm{BC}_{1} \mathrm{~s}$ and they both produced similar amounts to $T$. repens but of a higher sugar concentration. Other substances (volatiles) have been suggested as important in the attraction of pollinators. Their importance in $T$. nigrescens and the derived hybrids merits investigation.

Disomic inheritance and the prevalence of regular pairing and disjunction of the chromosomes at meiosis have indicated that $T$. repens is an amphidiploid (Atwood and Hill, 1940). A number of research workers have suggested that $T$. nigrescens may be one of the possible ancestors of $T$. repens (Brewbaker \& Keim, 1953; Hovin, 1962). A survey at the $P G I / 2$ locus of $T$. repens strongly suggested that $T$. repens behaves as an amphidiploid in which one of its genomes expresses a multiallelic series whilst the other is homozygous for the $c$ allele (Michaelson-Yeates, 1986). The results of the $P G I / 2$ survey in this paper revealed that, out of the five alleles found in $T$. repens, the only one that could be identified with a band in $T$. nigrescens was the $c$ allele. Although all chromosomes from $T$. repens and $T$. nigrescens are present in the $\mathrm{F}_{1} \mathrm{~s}$, the expression of $P G I / 2$ alleles from $T$. repens seems to be suppressed except for the $c$ allele. This was not evident in the $\mathrm{BC}_{1}$ generation as four alleles common to those that exist in $T$. repens were observed. The banding patterns of the $F_{1}$ s could also be explained if all five $T$. repens parents in the original hand-crosses were homozygous for the $c$ allele. Although the banding patterns of the original parents are not known, the probability of all five plants of $T$. repens being homozygous for the $c$ allele is extremely low. The results warrant further investigation of chromosomal behaviour in the hybrids at the PGI/2 locus.

This study has further demonstrated that certain cross-combinations between the two species can produce large numbers of hybrids without resorting to artificial techniques, indicating a close relationship between $T$. repens and $T$. nigrescens. Useful genetic variation in the form of reproductive characters can therefore be exploited by the plant breeder as a possible means of improving the seed production of $T$. repens. These hybrids along with their parental species 
may also provide information on the control of the various biochemical and developmental pathways associated with these reproductive characters.

\section{Acknowledgements}

The authors wish to thank Dr M. O. Humphreys for constructive criticism of the manuscript.

\section{References}

ATWOOD, S. S. AND HILL, H. D. 1940. The regularity of meiosis in microsporocytes of Trifolium repens. Am. J. Bot., 27, 730-735.

BREWBAKER, J. L. AND KEIM, w. F. 1953. A fertile interspecific hybrid in Trifolium $(4 \mathrm{n} T$. repens $\mathrm{L} . \times 4 \mathrm{n} T$. nigrescens Viv.). Am. Nat., 87, 323-326.

CORKILL, L. 1971. Leaf markings in white clover. J. Hered., 62, 307-310.

ERITH, A. G. 1924. White Clover-A Monograph. Duckworth and Co., London.

GIBSON, P. B., CHEN, C. C., GILlinghAM, J. T. AND BARNETT, O. W. 1971. Interspecific hybridization of Trifolium uniflorum L. Crop Sci., 11, 895-899.

HILL, J., NORRIS, I. B. AND MICHAELSON-YEATES, T. P. T. 1989. The inheritance of floral characters in white clover (Trifolium repens). Ann. Appl. Biol., 115, 101-113.
HOLLINGTON, P. A., MARShALL, A. H. AND HIDES, D. H. 1989. Effect of seed crop management on potential seed yield of contrasting white clover varieties. II. Seed yield components and potential seed yield. Grass and Forage Sci., 44, 189-193.

HOVIN, A. W. 1962. Interspecific hybridization between Trifolium repens $\mathrm{L}$. and $T$. nigrescens $\mathrm{Viv}$. and the analysis of hybrid meiosis. Crop Sci., 2, 251-254.

KEIM, W. F. 1953. Interspecific hybridization in Trifolium Utilizing embryo culture techniques. Agron. J., 45, 601-606.

MARSHALL, A. H., HOLLINGTON, P. A. AND HiDES, D. H. 1989. Effect of seed crop management on potential seed yield of contrasting white clover varieties. I. Inflorescence production. Grass and Forage Sci., 44, 181-188.

MARSHALL, A. H. 1994. Seasonal variation in the seed yield components of white clover. Plant, Varieties and Seeds, 7 , 97-105.

MICHAElson-yeates, T. P. T. 1986, Phosphoglucoisomerase variation in Trifolium repens. Genetica, 70, 53-58.

THOMAS, R. G. 1981. Effect of defoliation on flower initiation in white clover in summer. Grass and Forage Sci., 36, 121-125.

TRIMBLE, J. P. 1951. Interspecific Hybridization Studies in the Genus Trifolium. M.S. Thesis, Pennsylvania State College.

wILliams, E. 1978. A hybrid between Trifolium repens and $T$. ambiguum obtained with the aid of embryo culture. N. Z. J. Bot., 16, 499-506.

WILLIAMS, R. D. 1925 . Self and cross-sterility in white clover. Bull. Welsh Pl. Breed. Station, Series H., 12, 209-220. 